\title{
WEBINAR: Asian states and their diasporas
}

Edition 8, 2021

DOI: 10.37839/MAR2652-550X8.21

Recent decades have seen an increasing number of states adopt diaspora policies, establish government bodies dedicated to emigrants, or otherwise seek to engage strategically with their diasporas.

In this presentation and panel discussion, Yan Tan, Robi Rado and Andrew Rosser examine this phenomenon as it relates to three Asian states with large diasporas China, India and Indonesia.

The discussion explores how these Asian states engage with their diasporas, the drivers of, and obstacles to, diaspora engagement, and the implications for development in these countries and beyond.

Image: Genesha figure. Credit: Artem Beliaikin/Pexels. 